\section{Iron-induced esophageal ulceration}

Esophageal inflammation or ulceration is a well recognized side-effect of some oral medications, especially nonsteroidal anti-inflammatory or potassium chloride tablets. A similar injury can be induced by iron but endoscopically detected lesions are rarely reported $[1,2]$.

An 82-year-old woman presented a sudden complaint of dysphagia after ingestion of a ferrous sulphate tablet. She had chronic esophageal reflux and Raynaud's syndrome. Her physical examination was normal.

An upper endoscopy revealed a blackbrown, ulcerated and necrotic lesion, just below the upper esophageal sphincter, $2 \mathrm{~cm}$ in length, well circumscribed and associated with a slight stenosis. Below the lesion the esophageal lumen was distended and atonic, with candidiasis and a grade D peptic esophagitis ( Fig. 1, - Video 1).

Histological evaluation revealed ulcerated esophagitis, with acute inflammatory granulation tissue containing abundant brown crystalline nonbirefringent material, confirmed as iron by Perl's staining ( $\bullet$ Fig. 2,3). Other stainings for brown pigments and infections were negative.

The patient's iron tablets were stopped and a high dose proton pump inhibitor was prescribed. The dysphagia was relieved and a repeat upper endoscopy revealed progressive resolution of the necrosis and stenosis ( $\bullet$ Fig. 4, $\odot$ Video 2 ). Iron-induced esophageal erosions or ulcerations are seldom described and the differential diagnoses might be striking. Tablet debris seen at endoscopy is diagnostic but rarely detected. Histological examination reveals a typical brown crystalline material positive with Perl's staining $[1,3,4]$. The pathogenesis is believed to be a high local iron saturation causing a concentration-dependent absorption, resulting in the formation of reactive oxygen metabolites and mucosal injury [3]. Anatomical factors such as motility disorders or previous inflammation might predispose to the iron injury $[3,4]$.

\section{Video 1}

Upper endoscopy at day 1 revealed a blackbrown, ulcerated and necrotic lesion, just below the upper esophageal sphincter and a distended atonic esophagus.

Bibliography
Treatment requires stopping the offending drug or, if iron is still necessary, changing to a liquid preparation $[3,5]$. Iron-induced lesions are not endoscopically specific and histological investigation is essential to the diagnosis.

Endoscopy_UCTN_Code_CCL_1AB_2AC_3AZ

\section{Areia ${ }^{1}$, R. Gradiz ${ }^{1}$, P. Souto ${ }^{1}$,}

E. Camacho ${ }^{1}$, M. R. Silva ${ }^{2}$, N. Almeida ${ }^{1}$,

A. Rosa ${ }^{1}$, M. F. Xavier da Cunha ${ }^{2}$,

\section{C. Leitão ${ }^{1}$}

Department of Gastroenterology,

Coimbra University Hospital, Coimbra,

Portugal

2 Department of Pathology, Coimbra University Hospital, Coimbra, Portugal

\section{References}

1 Abbarah TR, Fredell JE, Ellenz GB. Ulceration by oral ferrous sulfate. JAMA 1976; 236 : 2320

2 Zhang ST, Wong WM, Hu WH et al. Esophageal injury as a result of ingestion of iron tablets. J Gastroenterol Hepatol 2003; 18: 466- 467

3 Abraham SC, Yardley JH, Wu TT. Erosive injury to the upper gastrointestinal tract in patients receiving iron medication: an underrecognized entity. Am J Surg Patho 1999; 23: 1241 - 1247

4 Eckstein RP, Symons P. Iron tablets cause histopathologically distinctive lesions in mucosal biopsies of the stomach and esophagus. Pathology 1996; 28: $142-145$

5 Haig A, Driman DK. Iron-induced mucosal injury to the upper gastrointestinal tract. Histopathology 2006; 48: 808 - 812

DOI $10.1055 / \mathrm{s}-2007-966820$

Endoscopy 2007; 39: E326

(c) Georg Thieme Verlag KG Stuttgart · New York . ISSN 0013-726X

\section{Corresponding author}

\section{Areia, MD}

Department of Gastroenterology

Coimbra University Hospital

3000-075 Coimbra

Portugal

Fax: +351-239-701517

miguel.areia@netcabo.pt

\section{Video 2}

Upper endoscopy at day 8 showing the progressive resolution of the lesion with a circumferential brown-pigmented lesion with no necrosis or stenosis.

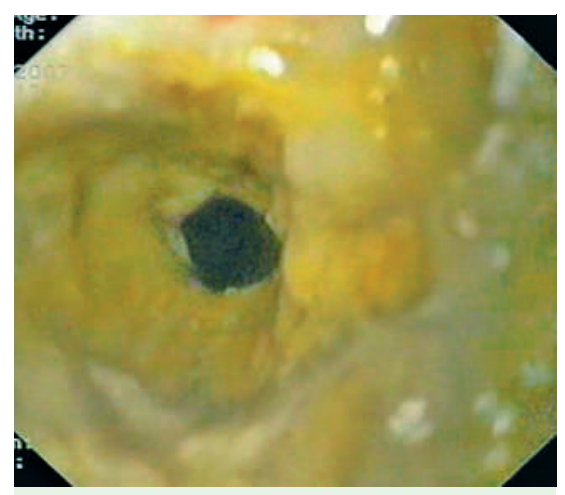

Fig. 1 Upper endoscopy at day 1 revealed a black-brown, ulcerated and necrotic lesion, just below the upper esophageal sphincter.

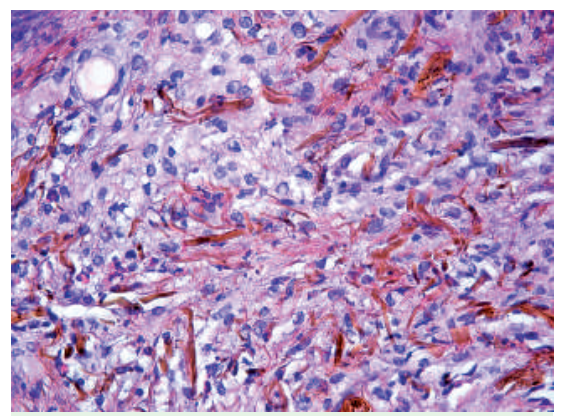

Fig. 2 Granulation tissue from the area with ulcerated esophagitis containing abundant brown crystalline material (hematoxylin and eosin, $\times 400$ ).

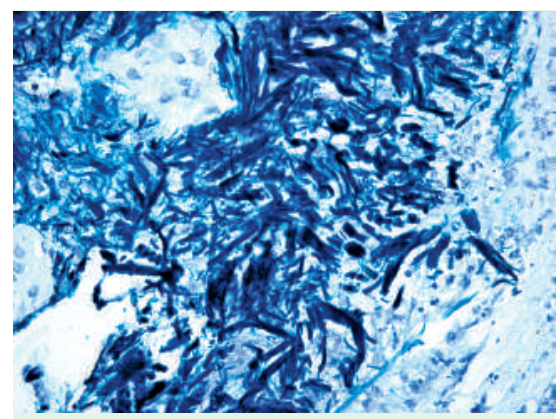

Fig. 3 Positive blue staining of the crystalline material with Perl's iron stain $(\times 400)$.

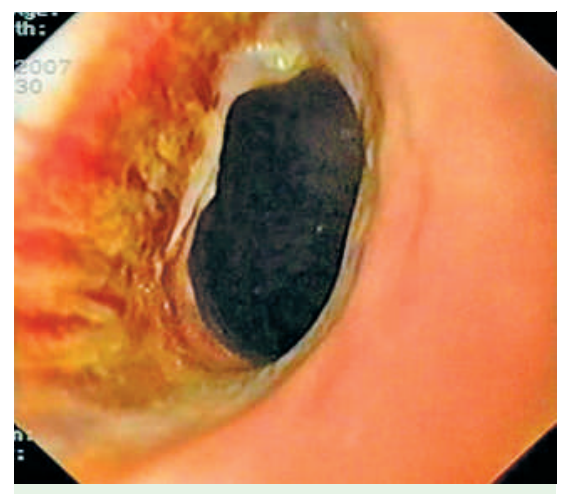

Fig. 4 Upper endoscopy at day 8 showing the progressive resolution of the lesion, with a brown pigmentation and no necrosis. 